\title{
El arpa y la sombra en el marco de la "nueva novela histórica" de América Latina
}

\author{
The Harp and the Shadow in the Framework \\ of the "New Historical Novel" of Latin America
}

\author{
Karen Elizabeth FLORES BonILlA \\ Facultad de Filosofía y Letras \\ Benemérita Universidad Autónoma de Puebla | México \\ Contacto: floresbonillak@yahoo.com.mx
}

\section{Resumen}

El artículo tiene como objetivo analizar las estrategias narrativas presentes en El arpa y la sombra de Alejo Carpentier (1979) que comprenden lo que la teoría literaria actual ha identificado como la "nueva novela histórica" latinoamericana. Primero se proporciona un breve panorama de la novela histórica tradicional y su contexto de aparición durante el romanticismo europeo del siglo XIX, a partir de las aportaciones de Georg Lukács (1966), con la intención de diferenciar su modelo del correspondiente a la producción posterior en este género. A continuación se ofrece una caracterización general de la novela histórica escrita en América Latina a partir de las décadas finales del siglo Xx, para reconocer las circunstancias histórico-sociales que dieron lugar a su renovación y a los rasgos que la determinan, junto con las propuestas de Mentón (1993) y Aínsa (1991) sobre el papel fundamental de Carpentier en su constitución. Finalmente, se realiza el estudio de cada uno de los aspectos señalados (distorsión consciente de los eventos históricos, ficcionalización de las grandes figuras históricas, uso de la primera persona en la narración, el dialogismo y la polifonía) con el objeto de demostrar la pertenencia de El arpa y la sombra a este reciente tipo de textos.

Palabras clave: nueva novela histórica, discurso historiográfico, dialogismo, polifonía, Cristóbal Colón, Alejo Carpentier, El arpa y la sombra

\begin{abstract}
The article aims to analyze the narrative strategies present in Alejo Carpentier's The Harp and the Shadow (El arpa y la sombra, 1979) that comprise what current literary theory has identified as the Latin American 'new historical novel'. First, a brief description of the traditional historical novel and its context of appearance during the European romanticism of the 19th century is provided, based on Georg Lukács's (1966) contributions, to differentiate its model from that of the subsequent production in this genre. The following is a general characterization of the historical novel written in Latin America from the last decades of the 20th century, to recognize the historical-social circumstances that led to its renewal and the features that determine it, together with the proposals of Menton (1993) and Aínsa (1991) on the fundamental role of Carpentier in its constitution. Finally, the study of each indicated feature - conscious distortion of historical events, the fictionalization of significant historical figures, use of the first person in the narration, dialogism, and polyphony - is carried out to demonstrate the belonging of The Harp and the Shadow to this recent type of texts.
\end{abstract}

Keywords: new historical novel, historiographical discourse, dialogism, polyphony, Christopher Columbus, Alejo Carpentier, The Harp and the Shadow 
Y diga el autor, escudándose con Aristóteles, que no es oficio del poeta (o digamos: del novelista) el contar las cosas como sucedieron, sino como debieron o pudieron haber sucedido.

-Alejo Carpentier (1979: 4)

\section{Introducción}

E l arpa y la sombra es la última novela del escritor cubano Alejo Carpentier publicada en 1979. La obra, dividida en tres apartados, introduce en el primero la propuesta de beatificación de Cristóbal Colón por parte del Papa Pío IX, quien en la vejez rememora sus viajes por América y los motivos que lo condujeron a plantear dicha solicitud ante la Sacra Congregación de Ritos. En la segunda sección, núcleo del texto, el propio almirante reflexiona desde su lecho de muerte sobre una vida marcada por la obsesión del oro y la gloria, por la presencia de amoríos prohibidos y travesías a los confines del mundo conocido, por abusos de poder, engaños y esclavitud. Así, tras este examen de conciencia narrado en primera persona, la última parte de la novela enfoca al fantasma de un Colón que se presenta a la asamblea vaticana encargada de considerar su petición de culto, lo que convierte al almirante en testigo directo de las inexactas representaciones que sobre él ha formulado el discurso historiográfico a través de los años. Ahora bien, el artículo busca en primer lugar explicar cómo surge la novela histórica tradicional en cuanto género literario, inscrito en los procedimientos narrativos del romanticismo europeo del siglo xIX, con la intención de diferenciar su modelo del correspondiente al conjunto de obras históricas escritas en América Latina a fines del siglo xx denominadas por la teoría literaria como "nuevas novelas históricas". En segundo lugar, busca describir el contexto histórico y las razones que motivaron esta renovación del género que se aparta de su modelo predecesor tanto en la forma como en el contenido. Por último, a partir de los rasgos comunes en la producción actual de novelas históricas, se analizan las características presentes en El arpa y la sombra que permiten demostrar su pertenencia a este reciente tipo de textos: el cuestionamiento al discurso histórico, la distorsión consciente de los hechos, la ficcionalización de personajes reconocidos, el uso de la primera persona, el dialogismo y la polifonía. Con base en esos objetivos, se recurre a la obra de Georg Lukács $(1966)^{1}$ para abordar teóricamente

\footnotetext{
1 Existen diversas propuestas respecto al surgimiento de la novela histórica en cuanto género literario, hecho del que se deriva la serie de múltiples conceptualizaciones sobre este tipo de textos que dependen del grado de implicación que se reconozca entre su aparición y el contexto histórico en que emergieron. De las primeras obras en abordar el tema y que, además, ha sido retomada por numerosos autores se encuentra La novela histórica de Lukács (1966); un texto teórico por excelencia para el estudio de este género y su manifestación en la historia literaria.
} 
el concepto de novela histórica y a las aportaciones de Aínsa (1991), Menton (1993) y Pons (1996) junto a trabajos previos sobre esta novela de Carpentier.

\section{La novela histórica tradicional}

De acuerdo con Georg Lukács (1966) la modificación que sufrió el concepto de Historia a partir de las dos últimas décadas del siglo XVIII fue determinante para el nacimiento de la novela histórica en tanto género literario. ${ }^{2}$ Hasta esa época, el término historia se había utilizado con la intención de justificar la inevitable renovación del feudalismo presente todavía en algunas comunidades europeas, consideradas irracionales y atrasadas por una élite ilustrada. Dicha concepción dio lugar a una búsqueda de la pasada grandeza de los estados de la Antigüedad clásica, retomados como modelo para la conformación de una sociedad más justa y culta. A pesar de este hecho, sería a raíz de los acontecimientos transcurridos en la Revolución Francesa (1789), junto con el auge y la posterior caída de Napoleón Bonaparte (1815), que "la Historia se convirtió (realmente) en una experiencia de masas" (Lukács, 1966: 20). Así entonces, durante el periodo que comprende los sucesos ya referidos, cada nación europea atravesó por un mayor número de movimientos sociales y alteraciones en sus estructuras de poder en comparación con siglos precedentes, derivando por primera vez en la consciencia de la historia como un ininterrumpido proceso de cambio que interviene en la sociedad y, por ende, en la vida de todo individuo (Lukács, 1966: 25).

De esta manera se dio lugar a dos acepciones del concepto de historia: a) la primera como "devenir histórico", es decir, como referente del transcurrir humano a través del tiempo; b) la segunda, como una "construcción discursiva" documentada en textos historiográficos (Pons, 1996: 56). En consecuencia, tal transformación en la concepción de la historia motivó el surgimiento de la novela histórica, un género literario nacido a inicios del siglo XIX con la obra del escritor británico Walter Scott. ${ }^{3}$ Sin embargo, a diferencia de textos previos en los cuales la historia se utilizaba como telón de fondo para la narración de las acciones de los protagonistas, pues tanto su forma de pensar como

2 El género literario comprende un método y medio de percibir, conceptualizar y evaluar una realidad (Bajtín, 1995: 133). Por lo tanto, implica una manera específica de escribir y de leer, cualidades que generan en el lector una "predisposición frente al texto" determinada por el contrato de lectura que el género establece a partir de sus rasgos convencionales.

3 Algunos autores difieren de Lukács (1966) en cuanto al surgimiento de la novela histórica. Por ejemplo, Galván (1996) señala que la novela histórica nace en el siglo XviII con la "novela gótica" y si bien reconoce a la obra de Walter Scott como parte de su evolución, no le otorga un papel preponderante. Por lo tanto, destaca la producción de otros escritores como Charles Dickens con Historia de dos ciudades de 1859 y George Eliot con Romola de 1863 (Galván, 1996: 91). 
las costumbres descritas en la obra pertenecían por completo a la época de su autor, este género reexperimenta las tendencias sociales del periodo histórico que recrea. De esa forma, las fuerzas contendientes en los eventos históricos son representadas en el destino y la vida de los personajes (Pons, 1996: 49); y así, la novela histórica demuestra la influencia que tienen los acontecimientos históricos en la cotidianidad, en la vida privada y personal de cada individuo. En definitiva, éste fue el modelo tradicional del género propuesto por Scott, replicado durante todo el siglo XIX y parte del Xx: un ejemplo es la novela Los novios de Alessandro Manzoni (1842), ambientada entre 1628 y 1630, donde se evidencia la repercusión de sucesos históricos, como el control austriaco sobre Lombardía, en el día a día de Renzo y Lucía, sus protagonistas.

\section{La nueva novela histórica de finales del siglo $\mathrm{xx}$}

No obstante, teóricos y críticos literarios han señalado, en los últimos años, ciertas modificaciones en el modelo tradicional del género planteado por Scott. ${ }^{4}$ De acuerdo con Rubiano (2001), la novela histórica en América Latina surge a fines del siglo xIx, junto al movimiento romántico importado de Europa, con el objeto de "crear una conciencia nacional y familiarizar a los lectores con los sucesos y personajes del pasado" (137). De hecho, su esquema mantuvo en el continente la forma inicial planteada por Scott.

Sin embargo, a partir del último tercio del siglo xx este paradigma manifestó cambios motivados por una reestructuración en la construcción del pensamiento que influyó en todas las áreas de estudio y que puso en duda sus principios. En el caso particular de la historia como ciencia se fortalece la idea de que el conocimiento histórico es producido únicamente en y por el lenguaje. De ese modo, no se define la historia "como suceder [...] pues el pasado sólo es cognoscible a través del discurso. De ello se deduce que es el relato del pasado el que lo convierte en historia" (Grinberg Pla, 2000). En definitiva, dicha transformación conceptual estuvo determinada por una crisis económica, social y política que América Latina enfrentó tras la década de los setenta del siglo pasado, con el resurgimiento de las dictaduras y el incremento del crimen organizado y las corporaciones paramilitares (Pons, 1996: 15). En este contexto nace la nueva novela histórica,

\footnotetext{
4 Las diferencias presentes en obras literarias escritas en Latinoamérica en las décadas finales del siglo xx han suscitado la aparición de amplias bibliografías en un intento de describir este fenómeno: las discusiones al respecto giran en torno al carácter innovador de los nuevos textos y tienen como propósito determinar si constituyen un testimonio de la ruptura del género literario histórico o sólo una prueba de su evolución. Así pues, el tema ha despertado el interés de numerosos académicos entre los que se encuentran también Morales Piña (2001), Campanella (2003), Grützmacher (2006) y Morales Jasso y Bañuelos Aquino (2017), quienes analizan los conceptos de novela histórica y nueva novela histórica, así como la pertinencia de su empleo y contexto de aparición.
} 
la cual marca un cambio radical puesto que estas obras se distancian del modelo tradicional de Scott "en lo que respecta a los aspectos formales de su narrativa y a la posición que adoptan frente a la Historia y a la historiografía" (Pons, 1996: 16).

De esta manera, se dio inicio al cuestionamiento de la Historia en tanto discurso oficial, colocando en el terreno de discusión la objetividad de los textos históricos reconocidos por la tradición, así como la existencia de una Verdad única e imparcial. Según Fernando Aínsa (1991), dichas novelas latinoamericanas proponen por primera vez una "reelectura demitificadora del pasado" (13), es decir, tienen como propósito el reescribir con un interés crítico la historia del continente. En esta línea, Seymour Menton (1993: 49) señala como la causa más importante en la creación de este tipo de obras literarias la aproximación del quinto centenario del descubrimiento de América. En definitiva, la nueva novela histórica se convirtió en el medio para la denuncia político-social de procesos y hechos históricos latinoamericanos al ofrecer una contrarréplica literaria del discurso histórico oficial. Por consiguiente, la mayor parte de su producción inicial se centró en la figura de Cristóbal Colón con la intención de reescribir su discurso y cuestionar desde sus cimientos la imposición del poder colonial en América. Porque, tal como apunta Rosa Pellicer (2004) en sus estudios sobre dicho tipo de textos, las novelas del género que retratan este acontecimiento no son pocas: El arpa y la sombra (1979) de Carpentier, El mar de las lentejas (1979) de Benítez Rojo, Los perros del Paraíso (1983) de Abel Posse, Memorias del Nuevo Mundo (1988) de Homero Aridjis, Vigilia del Almirante (1992) de Augusto Roa Bastos, Las puertas del mundo (1992) de Herminio Martínez, entre otros. En efecto, el impacto de las obras es tal que, dentro de las reflexiones sobre el papel de la novela histórica en la posmodernidad, académicos como Karl Kohut afirman que la novela histórica actual alcanza una importancia sólo comparable a la aparición de este género literario en el romanticismo del siglo XIX (Kohut, 1997: 20).

Por otra parte, autores como Menton (1993), Aínsa (1991) y Rodríguez Sancho (2003) coinciden en reconocer al cubano Alejo Carpentier como el precursor e iniciador de la renovación de este género narrativo. En su obra El reino de este mundo (1949), el escritor distorsiona los acontecimientos de la revolución haitiana de 1804 y omite la participación de personajes clave como Toussaint L'Ouverture y Jacques Dessalines con la intención de provocar una "evidente tensión con lo propuesto por la Historia convencional que los ha presentado desde las cumbres del prestigio y la gloria revolucionaria" (Rodríguez Sancho, 2003: 80). Si bien otros autores como Carlos Fuentes, Jorge Luis Borges y Augusto Roa Bastos también han jugado un papel determinante en la configuración de la nueva novela histórica, la figura de Carpentier como pionero de esa nueva narrativa se debe al camino trazado por el escritor en cada una de sus obras posteriores, desde el cuento largo "El camino de Santiago" (1954) hasta su última novela publicada, 
El arpa y la sombra (1979), en la que por primera vez el protagonista es un personaje histórico reconocido: el mismo Cristóbal Colón. Por tanto, El arpa y la sombra constituye el punto final en la evolución del género histórico dentro de la obra de Carpentier pues a diferencia de novelas anteriores como El siglo de las luces (1962), caracterizadas por una mayor fidelidad al discurso historiográfico (Aínsa, 1991: 17), este texto recupera el lado oculto de la historia del continente, recela de la verdad de los eventos históricos que enmarcan su descubrimiento y cuestiona la imagen mítica e idealizada del renombrado Cristóbal Colón. Es más, El arpa y la sombra constituye para Carpentier el final de un proyecto narrativo que le ocupó la vida entera, y éste fue el de pensar América (Palmero González, 2007: 107).

\section{El arpa y la sombra: elementos de la nueva novela histórica en la obra de Carpentier}

El carácter cuestionador propio de la nueva novela histórica se deriva de sus estrategias narrativas. Así, se han identificado una serie de rasgos característicos que la diferencian de la producción anterior en este género literario. En particular, su renovada actualidad no se ha traducido en un solo modelo estético de novela histórica ya que, de hecho, su aparición marca el fin del esquema único introducido por Scott. No obstante, en la variedad de sus expresiones se reconocen caracteres en común que dan lugar a un análisis más profundo de la relación entre literatura e historia. En ese sentido, los textos ofrecen una relectura del discurso histórico motivada por la percepción de la Historia como una ciencia no neutral, pues es "usada como arma para el combate ideológico en diferentes momentos y lugares del mundo" (Rodríguez Sancho, 2003: 73). Asimismo, es frecuente en estas obras la ficcionalización de personajes históricos distinguidos que, desde una narración en primera persona, distorsionan los acontecimientos y proponen otra visión de los hechos recreados. Por lo tanto, la presencia de conceptos bajtinianos como el dialogismo y la polifonía son incluso una constante. Ahora bien, a pesar de que la intertextualidad ${ }^{5}$ en dicha novela de Carpentier ha despertado un mayor interés por parte de la academia, ${ }^{6}$ las demás cualidades ya descritas de este nuevo género se encuentran

5 Como señala Mompó Valor (2007), la intertextualidad es un hecho consustancial en la literatura hispanoamericana desde sus inicios. Así, no resulta extraño que Carpentier estructure su última novela a partir de una conjunción de voces de otros autores, provenientes de distintas épocas y lugares, que han abordado también la cuestión del Descubrimiento.

6 En realidad, la mayoría de las investigaciones sobre El arpa y la sombra giran en torno a la relación existente entre la obra de Carpentier y otros textos, sean tanto literarios como históricos: Sarango Jaramillo (2018) se enfoca en su vínculo con los Diarios de Colón, Lois (2004) con los viajes de Marco Polo, y Mompó Valor (2007) con El libro de Cristóbal Colón del francés Paul Claudel. En efecto, se han estudiado ampliamente las relaciones 
también en El arpa y la sombra y posibilitan, de igual manera, un acercamiento al proceso de reconstrucción de la Historia desde la literatura.

\section{Un cuestionamiento al discurso oficial: la distorsión consciente de los sucesos históricos}

Esta novela de Carpentier se caracteriza por distanciarse de la versión historiográfica, respaldada por la tradición, de los eventos que enmarcan el descubrimiento del Nuevo Mundo. En efecto, la intención de su autor se evidencia, desde un inicio, con las siguientes palabras: "este pequeño libro debe verse como una variación sobre un gran tema que sigue siendo, por lo demás, misteriosísimo tema..." (Carpentier, 1979: 4). En definitiva, la relación que Carpentier había mantenido con la historia a lo largo de toda su producción previa se invierte en El arpa y la sombra, al optar por la perspectiva del poeta en vez del rígido punto de vista del historiador (Pellicer, 2004: 181). En este sentido, en la obra acontecen sucesos no referidos en el discurso histórico con el objeto de distorsionar la concepción oficial de los hechos y, de ese modo, cuestionar su validez. Éste es el caso de la travesía de Colón a la isla de hielo efectuada en la novela durante su juventud. Este pasaje narrado en primera persona aproxima a un inexperto Cristóbal Colón que, en su breve estadía por Islandia, se reencuentra con el maestre Jacob, un viejo amigo establecido en la región que domina la lengua y las historias contadas por los habitantes locales sobre los pueblos nórdicos. Sus sagas, en especial la Flateyjarbók escrita en los últimos años del siglo XII, describen la partida de Leif Erickson, junto a hombres de la recién instalada colonia nórdica en Groenlandia, y su llegada a Vinlandia, "la tierra del vino" (Almagro Basch, 1966: 326). Así pues, en la novela de Carpentier, Colón conoce los relatos antiguos sobre el arribo nórdico a Norteamérica siglos antes de su viaje al continente $y$, en consecuencia, se obsesiona con navegar de inmediato hacia el Oeste, no sólo por estar seguro de encontrar tierra firme tras el enorme océano Atlántico, sino también debido al temor que siente por perder esa posible fama de "descubridor"7 si otro marino se entera de la existencia de estos territorios:

intertextuales en la tercera parte de la novela, donde aparecen un sinfín de personajes que citan o aluden a otros textos para abogar o refutar la beatificación del marino. Sin embargo, la narración del propio Colón en el segundo apartado refiere también a obras como el Lazarillo de Tormes y la Celestina, relaciones examinadas por académicos como Velayos Zurdo (1990), Durán Luzio (1982), Padura Fuentes (1987), Valero Covarrubias (1989) y González Echeverría (1999).

7 Al respecto, Pellicer (2004: 183) señala que las novelas históricas sobre el Descubrimiento cuyo protagonista no es Colón se limitan a aludir al motivo del Paraíso como principal móvil del almirante. 
Sé a ciencia cierta que hay grande, poblada y rica tierra al Oeste; sé que navegando hacia el Oeste iría a lo seguro. Pero si viene a saberse de mi certeza [...] quedaría muy menguado el mérito de mi empresa. Peor aún: no faltaría el favorecido [...] que consiguiera las naves en mi lugar, y me birlara la gloria que tengo en mayor precio que cualquier otra honra. (Carpentier, 1979: 84)

En realidad, su preocupación no es para menos: la referencia al hallazgo vikingo de la isla canadiense de Terranova, efectuado alrededor del siglo XI, sí le niega a la primera travesía de Colón por América su carácter pionero. He ahí la importancia de retomar un pasaje clave de la historia ignorado por la tradición y que se constata incluso en los asentamientos de L'Anse aux Meadows ${ }^{8}$ cuyos trabajos de excavación se inspiraron, de hecho, en las sagas nórdicas (Wallace, 2009: 115). Ahora, diversos historiadores se habían cuestionado ya la supuesta intención de Cristóbal Colón de llegar a las Indias. De acuerdo con Acosta (1980) en su revisión de la bibliografía sobre el almirante, Colón tuvo conocimiento de tierras ubicadas a 150 leguas al suroeste de Portugal avistadas por un tal Diego de Teide, por lo cual "contaba con datos precisos, y no sólo con quimeras de visionario" (32). En efecto, si bien se han estudiado las fuentes que motivaron a Colón para hacerse a la mar en un intento de romper con esa imagen de explorador intrépido, la ciencia histórica ${ }^{9}$ coincide en refutar un posible conocimiento de la leyenda nórdica por parte de Colón y señala, a su vez, la serie de dificultades que los vikingos enfrentaron para transmitir su experiencia a las siguientes generaciones debido a la escasez de registros escritos (Lois, 2004) — una postura claramente divergente a la desviación histórica que estructura la trama de El arpa y la sombra.

En esta misma línea, el Cristóbal Colón que narra los sucesos desde su lecho de muerte no resulta el hombre representado por diversos textos historiográficos. En particular, Carpentier retoma el trabajo del Conde Roselly de Lorgues Historia de la vida y viajes de Cristóbal Colón, obra original dividida en tres tomos publicados entre 1858 y 1878. Ahora, a diferencia de lo relatado en la primera parte de la novela de Carpentier, este texto no presenta referencia directa de un posible encargo por parte del Papa Pío IX con el objeto de justificar la beatificación del almirante. No obstante, es evidente el motivo que condujo al autor cubano a retomar este escrito, ya que en él se acrecientan las virtudes del personaje e incluso se exhiben múltiples elogios hacia su persona: "muy pocos hombres habrán producido las edades de genio tan colosal como el protagonista de esta historia, pero ninguno habrá tan maltratado en su fama póstuma como Colón.

\footnotetext{
8 Traducido al español como "La ensenada de las medusas".

9 La tesis sobre el desconocimiento de Colón respecto a las historias nórdicas se basa principalmente en los trabajos de Henry Vignaud (1947) y Seymour Phillips (1994).
} 
Ya es hora, pues, de volver por los fueros de la verdad histórica hollada" (De Lorgues, 1878: 6). Así, Carpentier alude a dicha obra con el propósito de realizar una crítica irónica ${ }^{10}$ al retrato idealizado del marino que los historiadores han concebido por años. En efecto, su postura respecto a la configuración del almirante a partir del discurso histórico oficial se hace aún más explícita en el pasaje durante el cual Pío Nono reflexiona sobre el proceso de escritura de esta biografía:

Había pedido al Conde [...] que escribiese una verídica historia de Cristóbal Colón, a la luz de los más modernos documentos e investigaciones hechas acerca de su vida. Y en esa historia - la había leído y releído veinte veces - aparecía que el Descubridor de América era merecedor, en todo, de un lugar entre los santos mayores. Y [...] no podía haberse equivocado. Era un historiador acucioso, riguroso, ferviente, digno de todo crédito, para quien el gran marino había vivido siempre con una invisible aureola sobre la cabeza. (Carpentier, 1979: 53)

En este sentido, existe un cambio evidente entre el Colón configurado a partir del discurso historiográfico en la primera parte y el Colón humano que narra sus vivencias en la segunda: "marino desnortado [...] es cierto que, por voluntad de tu dueña, de prisa te fueron concedidas las órdenes menores franciscanas y que autorizado estás a usar el sayal sin capucha. Absurda porfía [...] ¡Fuego de lombardas y espíngolas ordenaría yo contra los Evangelios, puestos frente a mí, si me fuera posible hacerlo!" (Carpentier, 1979: 120). Incluso la división de la obra no es casual, pues permite advertir una exageración de la figura del almirante que el marino desmentirá a través de una confesión que abarca la mayor parte del texto. Por ende, en su intento de reescribir la historia, "Carpentier da una oportunidad a la otra historia, la hecha por hombres de carne y hueso y no por pretendidos héroes con afanes de hagiografía" (Souvirón López, 2001: 218). De hecho, en la tercera y última sección se aprecia mejor la dialéctica entre el discurso histórico oficial que presenta al almirante como un ídolo, y el discurso crítico alternativo de Carpentier que da voz a un simple humano encarnado por el propio Colón. Así, en "La sombra" el fantasma del marino acude a la asamblea vaticana que evalúa su propuesta de beatificación y, durante la sesión, se maravilla ante la cantidad de datos falsos y elogios que los historiadores refieren de los textos oficiales sobre su vida:

Un enfático resumen de lo que el Conde Roselly de Lorgues había expuesto, con lujo de apéndices y documentos probatorios. Al correr del discurso, cada vez más ditirámbico y vocativo, el Invisible se enternecía de gusto. ¿Cómo [...] ante la prueba de que poseía po-

${ }^{10}$ La ironía refiere "el empleo de una palabra con el sentido de su antónimo", es decir, implica un proceso de negación ya que el lector debe reconocer en ésta lo contrario de lo que se está diciendo (Ducrot y Todorov, 1974: 319). 
deres sobrenaturales, de los cuales jamás hubiese tenido idea, irían a vacilar sus jueces? (Carpentier, 1979: 200)

En definitiva, la crítica resulta evidente. De ahí que Colón obtenga también el favor de la corona española y el dinero suficiente para efectuar su travesía por América a partir de un amorío no documentado con la Reina Isabel de Castilla: "En las noches de su intimidad, Columba — así la llamaba yo cuando estábamos a solas - me prometía tres carabelas, diez carabelas, cincuenta carabelas, todas las carabelas que quisiera" (Carpentier, 1979: 102). Así pues, el marino manifiesta en numerosas ocasiones el amor que le profesa a la monarca; pasión caracterizada por el secreto y la fidelidad a su dama, cánones del amor cortés. Por tanto, la imagen de la soberana acompañará al almirante desde su primer encuentro en Santa Fe hasta más allá de su propia muerte: "Madrigal de las Altas Torres ${ }^{11}[\ldots]$ no entendieron la constancia de un desvelo tenido en secreto, porque forzoso era que fuera ignorado por todos, teniendo ambos que callar lo que acaso fue [...], a partir de cierta época, brújula y norte de mis actos" (Carpentier, 1979: 220). En consecuencia, la relación de subordinación retratada en el discurso historiográfico entre el marino y su reina se transforma en la novela de Carpentier en un romance. De hecho, Isabel mantiene aventuras con otros hombres de la corte como Martín Vázquez de Arce, un guerrero muerto en combate contra los moros de Granada a quien, según Colón, la soberana mandó construir un sepulcro en la Catedral de Santa María de Sigüenza: “el hermoso Doncel [...], perecido por extremarse en pruebas de valentía ante su Dama - inspiradora de sus afanes, guiadora de sus empeños. ¡Y cuántos celos tenía yo a veces de ese joven guerrero poeta!" (Carpentier, 1979: 102). En suma, dentro de El arpa y la sombra se distorsiona incluso el sólido matrimonio constituido por los Reyes Católicos que ha sido ampliamente descrito en numerosas investigaciones históricas posteriores. ${ }^{12}$

\section{Una ficcionalización de las grandes figuras históricas:} la ausencia del narrador omnisciente

Las transformaciones sociales en América Latina a fines del siglo xx provocaron un cambio radical en el estudio y análisis histórico, pues en contraste con los especialistas

11 En múltiples ocasiones a lo largo de la novela Colón se refiere a la reina por su lugar de nacimiento, Madrigal de las Altas Torres, un municipio de la provincia de Ávila, en Castilla.

12 A pesar de que el matrimonio de los Reyes Católicos fue arreglado a partir de las circunstancias políticas que atravesaba la Península, existe un consenso entre los historiadores respecto a que ambos conformaron una unión estable que permitió la configuración de España como uno de los primeros Estados modernos de Europa. Para más información consultar los trabajos de Zamora García (2006) y Rodríguez Valencia y Suárez Fernández (1960). 
del siglo XIX cuya concepción de la historia giraba en torno a la reconstrucción de la vida y obra de los grandes líderes (Menton, 1993: 43), el trabajo de los historiadores latinoamericanos en las últimas décadas ha optado por centrarse en grupos minoritarios como una forma de ampliar el conocimiento de un pasado que todavía no se ha contado. Tal modificación repercutió también en el esquema tradicional del género literario, pero de manera inversa, ya que a diferencia del modelo tradicional de Scott en el que los personajes principales eran en su mayoría ficticios, estas nuevas novelas se inclinan por presentar como protagonistas figuras históricas reales, entre las que se hallan Maximiliano, Carlota, Cortés, Magallanes y Guillermo Prieto. De este modo, no resulta una casualidad que en El arpa y la sombra sea el propio almirante el encargado de narrar su vida y, por tanto, de desmentir los mitos sustentados por la tradición respecto a su persona. En efecto, la producción anterior de Carpentier empleaba únicamente figuras históricas menores, casi desconocidas y marginadas de la historiografía como Paulina Bonaparte en El reino de este mundo y Victor Hugues en El siglo de las luces, junto a protagonistas que pertenecían por entero al imaginario de su autor (Acosta, 1980: 26). Por ende, al romper con este modelo en su última obra, Carpentier se posiciona como uno de los primeros en retomar personajes con un reconocimiento mayor para exhibirlos como protagonistas de sus novelas históricas - una estrategia que define, de hecho, la renovación de este género narrativo.

Así, la segunda parte de El arpa y la sombra se caracteriza por el uso de la primera persona, distanciándose del narrador omnisciente con conocimiento absoluto de los sucesos y pensamientos de los personajes que define el esquema de la novela histórica tradicional (Pons, 1996: 17). A pesar de estar narrados desde un punto de vista externo, los otros apartados enmarcan el relato de un Cristóbal Colón que refiere a viva voz la historia de su vida. En consecuencia, la confesión del almirante constituye la sección más extensa de la obra, donde el Colón ya moribundo adquiere una perspectiva histórica que le permite juzgar al otro Colón, al héroe descubridor del Nuevo Mundo. Con dicha estrategia, la figura parece duplicarse sobre sí misma. De esta forma, su relato oscila "entre el presente del yo-sujeto narrador y el pasado del yo-objeto narrado" (Palmero González, 2007: 109); es decir, "La mano" conforma la narración de un almirante que reflexiona, desde un presente que lo postra en su lecho de muerte, sobre un pasado que habla también a través de su propia boca:

sí, ahora que estoy en los umbrales de la muerte me aterra la palabra, pero en este memorial que releo está bien claramente escrita. [...] Pido licencia para la mercaduría de esclavos. Afirmo que los caníbales de estas islas serán mejores que otros ningunos esclavos (Ya que no doy con el oro, pienso yo, puede el oro ser substituido por la irremplazable energía de la carne humana). (Carpentier, 1979: 162) 
En este sentido, por medio de la narración en primera persona se superponen dos tiempos, lo que difumina la separación entre los distintos acontecimientos - una táctica denominada por Aínsa (1991) como la "abolición de la distancia épica"-. Por último, a partir de esta confesión de Colón comienzan a borrarse las versiones historiográficas sobre el Descubrimiento, transformando al segundo apartado en "un desvío que permite, desde la zona de lo privado, descubrir el proceso de construcción de una escritura histórica engañosa" (Souvirón López, 2001: 220). En efecto, el empleo de la primera persona da lugar a un Colón que desmiente y contradice la configuración que se ha hecho de él como figura histórica: "de repente me saqué de las mangas un tío almirante; me hice estudiante graduado de la Universidad de Pavía, cuyos claustros jamás pisé en mi jodida existencia; me hice amigo — sin haberle visto la cara — del rey Renato de Anjou y piloto distinguido del ilustre Coulon, el Mozo" (Carpentier, 1979: 95). Es entonces que, mediante la propia voz del almirante, se recupera un pasado hecho de ocultamientos y mentiras.

\section{Las nociones bajtinianas: dialogismo y polifonía}

Ahora bien, al criticar la verdad única defendida por el discurso histórico, estas nuevas novelas proyectan visiones dialógicas; esto es, exponen dos o más interpretaciones de los acontecimientos, de los personajes que participan en ellos y de la visión del mundo que los mueve a actuar. Porque, para Bajtín (1986), lo dialógico “es un fenómeno casi universal que penetra todo el discurso humano" (67) y, por tanto, se encuentra de forma intrínseca en la novela, campo para la representación de diferentes voces, personajes, hechos e ideologías como manifestaciones de la vida humana. Así pues, en la última parte de la obra de Carpentier se aprecia una conjunción de voces distintas que no permiten una lectura única del asunto que los ocupa: la beatificación de un hombre. El debate entre las posturas divergentes de la historia se desarrolla a través de la boca de figuras históricas anacrónicas que ofrecen acusaciones y defensas ante un Cristóbal Colón fantasma que en media discusión espera la sentencia del jurado más exigente, Carpentier, cuyo veredicto se hace explícito en las palabras del almirante: "con tu regalo de enfermedades ignoradas donde arribaste, en tus buques llevaste la codicia y la lujuria, el hambre de riquezas, la espada y la tea, la cadena, el cepo, [...] allí donde se te vio llegar como hombre venido del cielo" (Carpentier, 1979: 184). En definitiva, a partir de esta aglutinación de diferentes discursos y posturas autónomas se configura la novela polifónica, definida por esa pluralidad de voces y conciencias independientes que la constituyen (Bajtín, 1986: 15). En esta línea, "La sombra” proporciona la mayor cantidad de ejemplos, ya que durante la asamblea cada personaje adopta una posición 
en específico con respecto a la postulación del almirante. Por consiguiente, en el transcurso de la discusión en torno al cargo de concubinato, se establece un diálogo entre el Abogado del Diablo y el Presidente de la reunión, dos posturas confrontadas que introducen razones a favor de su posición en una disputa terciada por el propio Colón:

"¡Un poco de compostura!” — clama el Presidente. — "Esa joven, dechado de virtudes, a quien el gran hombre quería y respetaba..." — “Tanto la respetaba que le hizo un hijo" larga, casi grosero, el luciferino letrado: "Y Colón se sabía tan responsable del estropicio que acaso por tratar de remediarla en su soledad [...] cuando Rodrigo de Triana lanzó el grito famoso de ¡Tierra, Tierra! ...” - “Dejemos quieto a Rodrigo de Triana y el asunto de los 10000 maravedís, que mejor estaban en manos de una joven madre que en las de un marino cualquiera [...]" (—“Sí, sí, sí... Dejen tranquilo a Rodrigo de Triana porque si tras de él me vienen los Pinzón y mis criados, Salcedo y Arroyal, [...] mi causa se va a hacer puñetas"). (Carpentier, 1979: 214-215)

\section{Conclusiones}

En definitiva, a partir de lo expuesto se evidencia que El arpa y la sombra de Carpentier (1979) pertenece al conjunto de obras, escritas en América Latina desde la década de los setenta del siglo xx, denominada en los últimos años por la teoría literaria como nuevas novelas históricas. Primero, porque a diferencia del modelo tradicional de este género narrativo, el texto lleva a cabo una crítica al discurso historiográfico oficial de los sucesos que enmarcan el Descubrimiento de América y la versión consolidada de la figura de su descubridor. Por ende, en vez de presentarse como un héroe o un santo, Colón se describe a sí mismo como un hombre consciente de la inexactitud de las historias que se cuentan sobre los grandes personajes históricos. Asimismo, la distorsión consciente de los eventos y la recuperación de hechos no referidos en el discurso histórico a partir de la narración en primera persona conforman en Carpentier una manera de descolonizar la historia del continente. En esa misma línea, el entrecruzamiento de los distintos discursos que da lugar al dialogismo y que le otorga a El arpa y la sombra su carácter polifónico le permite al autor reescribir otra historia: es decir, inventar el pasado, cuestionar el discurso historiográfico y sus versiones que sostienen tópicos e imágenes fundantes de una supuesta identidad americana que, de hecho, ha sido impuesta por la tradición (Bravo Herrera, 2012: 90). Carpentier, a través de dichas estrategias narrativas, busca revelar la otra cara de un discurso que no corresponde a la realidad discursiva de América Latina. 


\section{Referencias bibliográficas}

Acosta, Leonardo. (1980). "El almirante, según don Alejo". Casa de las Américas, 21(121), 26-40.

AínSA, Fernando. (1991). "La reescritura de la historia en la nueva narrativa latinoamericana". Cuadernos americanos, Nueva Época, 4(28), 13-31. http://www.cialc. unam.mx/ca/ne/NE-28.pdf

Almagro Basch, Martín. (1966). "Prehistoria y huellas vikingas en el N. E. de América”. Atlántida, 4(21), 324-328.

Bajtín, Mijaíl. (1986). Problemas de la poética de Dostoievski (Tatiana Bubnova, Trad.). México: Fondo de Cultura Económica. (Obra original publicada en 1979).

BAJTín, Mijaíl. (1995). El método formal en los estudios literarios (Tatiana Bubnova, Trad.). Madrid: Alianza. (Obra original publicada en 1994).

Bravo Herrera, Fernanda Elisa. (2012). “(Auto)biografía e historia en El arpa y la sombra de Alejo Carpentier”. En Marta Álvarez y Antonio Gil González (eds.), Metanarrativas Hispánicas. Berlín: Editorial Lit Verlag. 83-92.

CAMPANElla, Noemí. (2003). La novela histórica argentina e iberoamericana hacia fines del siglo XX, 1969-1999. Buenos Aires: Vinciguerra.

CARPENTIER, Alejo. (1979). El arpa y la sombra. México: Siglo XXI.

De Lorgues, Roselly. (1878). Historia de la vida y viajes de Cristóbal Colón. Tomo I. (D. Pelegrin Casabó y Pagés, Trad.). Barcelona: Jaime Seix. (Obra original publicada en 1858).

Ducrot, Oswald; Todorov, Tzvetan. (1974). Diccionario enciclopédico de las ciencias del lenguaje (Enrique Pezzoni, Trad.). Argentina: Siglo XXI.

Durán Luzio, Juan. (1982). “Un nuevo Epílogo de la Historia: El Arpa y la Sombra, de Alejo Carpentier”. Casa de las Américas, (125), 100-110. 
GALvíN, Fernando. (1996). "Ficción histórica y metaficción historiográfica: el caso inglés". 1616: Anuario de la Sociedad Española de Literatura General y Comparada, 10, 91-97.

GonzÁlez EcheVerRía, Roberto. (1999). Alejo Carpentier: El peregrino en su patria. México: UNAM.

Grinberg Pla, Valeria. (2000, julio). "La novela histórica de finales del siglo xx y las nuevas corrientes historiográficas". V Congreso Centroamericano de Historia. Congreso celebrado en la Universidad Nacional de El Salvador, San Salvador. Recuperado el 2 de enero de $2021 \mathrm{de}$ http://istmo.denison.edu/n02/articulos/novhis.html

GrÜTZMACHER, Lukasz. (2006). "Las trampas del concepto 'la nueva novela histórica' y de la retórica de la historia postoficial". Acta Poética, 27(1), 141-167. http://dx.doi. org/10.19130/iifl.ap.2006.1.193

KoHUt, Karl. (1997). La invención del pasado. La novela histórica en el marco de la posmodernidad. Madrid: Publicaciones del Centro de Estudios Latinoamericanos de la Universidad Católica de Eichstätt.

Lois, Carla. (2004). "Cartografías de un Mundo Nuevo. Las geografías de Cristóbal Colón”. Terra Brasilis (Nova Série). Revista da Rede Brasileira de História da Geografía e Geografía Histórica, (6), 13-39. http://redebrasilis.net/TerraBrasilis/TerraBrasilis-6.pdf

LuKÁcs, Georg. (1966). La novela histórica (Jasmin Reuter, Trad.). México: Ediciones Era. (Obra original publicada en 1955).

Menton, Seymour. (1993). La nueva novela histórica de la América Latina 1979-1992. México: Fondo de Cultura Económica.

Mompó VALOR, Javier. (2007). "El arpa y la sombra: procesos intertextuales en la construcción del personaje de Cristóbal Colón”. América Sin Nombre, (9-10), 139-147. https://doi.org/10.14198/AMESN2007.9-10.19

Morales Jasso, Gerardo; Bañuelos Aquino, Víctor Manuel. (2017). "Debates en torno al concepto de 'novela histórica'. Propuestas desde el diálogo entre la historiografía y la crítica literaria”. Relaciones. Estudios de Historia y Sociedad, 38(152), 267-302. http:// dx.doi.org/10.24901/rehs.v38i152.361 
Morales Piña, Eddie. (2001). "Brevísima relación de la nueva novela histórica en Chile". Notas Históricas y Geográficas, (12), 177-190. https://www. revistanotashistoricasygeograficas.cl/index.php/nhyg/article/view/144

Padura Fuentes, Leonardo. (1987). Colón, Carpentier, la mano, el arpa y la sombra. La Habana: Universidad de la Habana.

Palmero González, Elena. (2007). "El último viaje a los orígenes de Alejo Carpentier: El arpa y la sombra". Contexto: Revista Anual de Estudios Literarios, 11(13), 105-118. http://erevistas.saber.ula.ve/index.php/contexto/article/view/10856

Pellicer, Rosa. (2004). “Colón y la busca del paraíso en la novela histórica del siglo xx (de Carpentier a Roa Bastos". América Sin Nombre, (5-6), 181-187. http://dx.doi. org/10.14198/AMESN2004.5-6.22

Phillips, Seymour. (1994). "The Outer World of the European Middle Ages". En Stuart Schwartz (ed.), Implicit Understandings. Observing, Reporting and Reflection on the Encounters between Europeans and Other Peoples in the Early Modern Era. Inglaterra: Cambridge University Press. 23-63.

Pons, María Cristina. (1996). Memorias del olvido. Del Paso, García Márquez, Saer y la novela histórica de fines del siglo XX. México: Siglo XXI.

Rodríguez SANCHO, Javier. (2003). "La nueva novela histórica: espacio para el encuentro entre literatura e historia en América Latina y el Caribe en la óptica de Carpentier”. InterSedes: Revista de las Sedes Regionales, 4(6), 69-84.

Rodríguez Valencia, Vicente; Suárez Fernández, Luis. (1960). Matrimonio y derecho sucesorio de Isabel la Católica. Valladolid: Facultad de Teología.

Rubiano, Martha Lucía. (2001). "La reescritura de la Historia en la Nueva Novela Histórica". Cuadernos de Literatura, 7(13-14), 136-142.

Sarango Jaramillo, Cristhian. (2018). "Análisis comparatístico de la novela El arpa y la sombra de Alejo Carpentier y los documentos y recursos sobre Cristóbal Colón”. Universidad Técnica Particular de Loja. Recuperado el 4 de enero de 2021 de https://www.researchgate.net/publication/327011552_Analisis_comparatistico_de la novela_El_Arpa_y_la_Sombra_de_Alejo_Carpentier_y_los_documentos_y_recursos sobre Cristobal_Colon 
SOUvirón LóPez, Begoña. (2001). "Entre El arpa y la sombra: la mano... Construcción y deconstrucción del personaje histórico y héroe mítico Cristóbal Colón en la obra de Alejo Carpentier". Anales de Literatura Hispanoamericana, 30, 207-225. https://revistas.ucm. es/index.php/ALHI/article/view/ALHI0101110207A

VAlero Covarrubias, Alicia. (1989). "El arpa y la sombra de Alejo Carpentier: una confesión a tres voces". Cuadernos Americanos, 3(2), 140-144.

Velayos Zurdo, Óscar. (1990). Historia y Utopía en Alejo Carpentier. Salamanca: Ediciones Universidad de Salamanca.

Vignaud, Henry. (1947). Cristóbal Colón y la Leyenda. Buenos Aires: Argos.

Wallace, Birgitta. (2009). "L'Anse aux Meadows, Leif Ericksson's Home in Vinland". Journal of the North Atlantic, 2(2), 114-125. https://doi.org/10.3721/037.002.s212

Zamora García, Francisco. (2006). "Isabel la Católica y el consentimiento matrimonial". Alcalibe: Revista Centro Asociado a la UNED, (6), 131-144. 